\title{
Macrophage Cell Biology
}

National Cancer Institute

\section{Source}

National Cancer Institute. Macrophage Cell Biology. NCI Thesaurus. Code C18866.

The structure and biological function of macrophages 